\title{
PEMBANGUNAN INDUSTRI PERTAHANAN INDONESIA: MENUJU PEMENUHAN TARGET MEF ATAU SEKEDAR MENUJU ARM CANDY?
}

\author{
Lukman Fahmi Djarwono $^{1}$
}

\begin{abstract}
Abstrak: MEF (Minimum Essential Force) merupakan standar penting dan minimum dari kekuatan yang harus ditetapkan sebagai prasyarat mendasar agar TNI (Tentara Nasional Indonesia) dapat menjalankan misinya secara efektif dalam menghadapi ancaman yang sebenarnya. Salah satu sarana untuk mewujudkan MEF adalah melalui pengembangan industri militer dalam negeri. Optimalisasi pengembangan industri pertahanan nasional baru saja diberlakukan sejak 2010 melalui Kebijakan Umum Pertahanan Negara (Jakum Hanneg) 2010-2014, dan akan berlanjut selama dua periode lima-tahun lagi (sampai 2024). Selama belum ada definisi yang jelas mengenai "keamanan nasional", masih sulit untuk membentuk postur pertahanan yang ideal. Oleh karena itu, pencapaian MEF masih akan menghasilkan kesenjangan kemampuan. Kesenjangan ini diharapkan dapat berkurang -jika tidak dihilangkandengan memiliki industri pertahanan nasional yang solid. Artikel ini akan mengeksplorasi peran industri pertahanan nasional untuk mencapai MEF, sekaligus untuk mengurangi kesenjangan kemampuannya di Indonesia.
\end{abstract}

Kata Kunci: Industri Pertahanan; Minimum Essential Force; Tentara Nasional Indonesia; Indonesia

\section{Pendahuluan}

Aman, merupakan salah satu hak asasi warganegara yang paling mendasar. Warganegara berhak mendapat situasi dan kondisi aman dalam melakukan segala aktivitas di suatu wilayah negara selama aktivitasnya tersebut tidak melanggar aturan maupun norma yang berlaku.

1 Penulis adalah staf pengajar Studi Strategi Keamanan dan Pertahanan di Prodi Hubungan Internasional, Fakultas IImu Sosial dan Politik, Universitas Sebelas Maret (UNS) Surakarta; peergroup Pusat Studi ASEAN dan PUSDEMTANAS UNS;serta staf pengajar tidak tetap di Prodi Hubungan Internasional FISIP Universitas Slamet Riyadi, Surakarta. Penulis dapat dihubungi melalui email lukman.f.d@staff.uns.ac.id atau lukman.f.d@gmail.com
Aman juga termasuk tujuan dari fungsi mutlak suatu negara, salah satunya adalah Fungsi Pertahanan (Budiardjo, 1999). Hal ini menjadi fungsi negara disebabkan kemungkinan adanya gangguan, serangan atau invasi militer dari luar, sehingga setiap negara yang merdeka dan berdaulat berkewajiban untuk mengamankan dan mempertahankan kedaulatan, keutuhan wilayah, dan keselamatan warganegaranya

Untuk membuat pertahanan suatu negara menjadi kuat, setidaknya diperlukan 2ED, yakni Economic Power (kekuatan ekonomi), Education for 
Reserve Personnel (pendidikan nasionalisme dan bela negara), dan Deterrent Effect (daya tangkis atau daya gentar).

Kekuatan ekonomi suatu negara berbanding lurus dengan sistem pertahanannya, hal ini dapat kita bandingkan secara kasat mata antara pertahanan developed countries dengan developing countries. Kekuatan di sektor ini tergolong vital dalam membangun benteng pertahanan di teritorinya, yang meliputi personil angkatan bersenjatanya maupun peralatan utama sistem persenjataannya.

Kita juga tidak dapat menafikkan bahwa daya tangkis atau gentar suatu negara menjadi salah satu unsur penting dalam kekuatan pertahanan. Membangun dan menyusun peralatan utama sistem persenjataan agar tidak hanya menjadi pemanis buatan saja, tetapi juga menjadi alat yang berfungsi untuk menggentarkan pihak lain yang ingin mengganggu kedaulatan, keselamatan dan keutuhan teritori negara.

Sebagaimana tertuang dalam amanat Pembukaan Undang-Undang Dasar Negara Republik Indonesia Tahun 1945 Republik Indonesia bahwa untuk membentuk suatu pemerintahan Negara Indonesia yang melindungi segenap bangsa Indonesia dan seluruh tumpah darah Indonesia, dan untuk memajukan kesejahteraan umum, mencerdaskan kehidupan bangsa, dan ikut melaksanakan ketertiban dunia yang berdasarkan kemerdekaan, perdamaian abadi, dan keadilan sosial.

Pada Perpres nomor 41 tahun 2010 tentang Kebijakan Umum Pertahanan Negara juga disebutkan bahwa Pertahanan negara bertujuan untuk menjaga dan melindungi kedaulatan negara, keutuhan wilayah Negara Kesatuan Republik Indonesia, dan keselamatan segenap bangsa dari segala ancaman. Maka dengan demikian, negara Indonesia berhak dan wajib untuk memiliki dan menyusun angkatan perang berikut sistem persenjataannya.

Pada kebijakan tersebut, Presiden Susilo Bambang Yudhoyono menyatakan bahwa strategi pertahanan Negara Republik Indonesia adalah bersifat defensif-aktif. Pun dijelaskan bahwa pengembangan dan peningkatan kekuatan armada perang Indonesia difokuskan pada perwujudan Minimum Essential Force (MEF / Kekuatan Pokok Minimum), sebagai prasyarat utama dan mendasar bagi terlaksananya tugas pokok dan fungsi TNI.

Prioritas utama perwujudan MEF yakni peningkatan kemampuan mobilitas TNI meliputi 3 (tiga) matra yakni Darat, Udara, dan Laut, untuk mendukung penyelenggaraan tugas 
pokok TNI di seluruh wilayah nasional. Kemudian prioritas selanjutnya adalah peningkatan kemampuan satuan tempur khususnya pasukan pemukul reaksi cepat serta penyiapan pasukan siaga terutama untuk penanganan bencana alam serta tugas-tugas misi perdamaian dunia seperti yang telah diamanatkan dalam Pembukaan UUD Negara Republik Indonesia tahun 1945.

Penulis berharap agar artikel ini dapat berguna sebagai refleksi dan ekspektasi postur pertahanan dan militer Republik Indonesia pada umumnya, dan terutama pengadaan alutsista melalui kemandirian industri pertahanannya di masa mendatang.

\section{Isi Penelitian}

Pembangunan alutsista sendiri, baru dimulai Indonesia pada 2010 yang dilaksanakan dalam beberapa tahap dimana tiap tahapnya berjarak waktu selama 5 tahun. Tahap I (pertama) MEF dimulai sejak tahun 2010 hingga tahun 2014, tahap II (kedua) akan berlangsung dari tahun 2015 hingga 2019, tahap III (ketiga) akan dilaksanakan dari tahun 2020 hingga 2024, dan tahap IV (keempat) akan direncanakan dari tahun 2025 hingga 2029.

Minimnya kemampuan industri pertahanan dalam negeri dan kurangnya ketersediaan peralatan pertahanan, serta ketergantungan pada produsen luar negeri dalam mengawali pijakan MEF tahap I menjadikan target pada tahapan lanjut MEF dapat terancam. Untuk menghindari ketergantungan dari produsen dan ingin menekan anggaran pembelanjaan dari produsen alutsista di luar negeri, maka Pemerintah Indonesia berinisiatif untuk memberdayakan potensi-potensi industri dalam negeri untuk menjadi pemasok bagi persenjataan dan armada perang TNI. Di tahun 2012, lahirlah Undang-Undang nomor 16 tentang Industri Pertahanan yang mengatur tentang pemanfaatan dan maksimalisasi industri pertahanan dalam negeri demi mencapai target MEF tahap I (pertama). Tujuan penguatan industri pertahanan ini adalah untuk memenuhi kebutuhan alutsista TNI guna tercapainya MEF pada tahun 2024, dan tujuan yang kedua adalah tercapainya kemandirian dalam pengadaan alutsista TNI di tahun 2029.

Pada APBN 2010, Pemerintah Indonesia menganggarkan 40,7 Trilyun untuk bidang pertahanan. Sedangkan di tahun 2012, pertahanan mendapat anggaran 72,54 Trilyun. Pada 2013, anggaran pertahanan mengalami peningkatan sebesar 77,7 Trilyun. Pada 2014 Pemerintah Indonesia menempatkan 86,3 Trilyun untuk bidang pertahanan. Anggaran alutsista untuk memenuhi MEF untuk 2010-2014 
mencapai Rp 156 triliun yang terdiri atas

Rencana Pembangunan Jangka

Menengah 2010-2014 sebesar Rp 99 triliun dan alokasi on top berdasar arahan rapat kabinet terbatas 4 Oktober 2010 sebesar Rp 57 triliun. $^{2}$

Anggaran pertahanan Pemerintah Indonesia yang meningkat dari tahun 2010 hingga 2014 dinilai cukup signifikan, akan tetapi Pemerintah Indonesia masih belum mengeluarkan kebijakan mendetail terkait pendefinisian ancaman yang dihadapai negara Republik Indonesia.

Pengadaan alutsista di tiga matra pada tubuh TNI tidaklah sama dalam kualitas maupun kuantitas, disesuaikan menurut kebutuhan dan proyeksi adanya ancaman di tiap matra. Pada TNI Angkatan Darat misalnya, di tahun 2015 yang lalu beberapa target alutsista yang akan dimiliki antara lain adalah 103 MBT Leopard II, 50 IFV Marder, 36 MLRS Astross II Mk6, 38 Howitzer Digital Caesar Nexter, 20 helikopter Bell 412Ep, beberapa helikopter lainnya, kendaraan taktis, juga beberapa panser Anoa, rudal, dan juga truk angkut pasukan. $^{3}$

Di tahun 2015 lalu juga, untuk pengadaan alutsista pada TNI Angkatan Laut, Pemerintah Indonesia

2 Diolah dari berbagai sumber

${ }^{3}$ MEF: Modernisasi Militer Indonesia pada website http://analisismiliter.com/artikel/part/20/MEF Modernisa si_Militer_Indonesia, diakses pada 29 Maret 2017 membutuhkan 37 tank amphibi BMP3F, 25 kendaraan amphibi LVTA1, 5 tank amphibi BTR-4, 10 MLRS RM Grad, 11 helikopter anti-kapal selam Panther, 4 helikopter angkut Bell 412Ep, 4 pesawat intai maritim CN235 MPA, beberapa kapal perang mulai dari jenis latih layar hingga jenis light fregat, 2 kapal selam Kilo, dan 2 kapal hidrografi. ${ }^{4}$

Sedangkan pengembangan dan modernisasi di TNI Angkatan Udara di tahun yang sama, akan didatangkan 12 pesawat tempur Super Tucano, 16 pesawat tempur T50i, 8 pesawat tempur F16 dengan menggunakan blok 52, 6 helikopter Cougar, 4 radar Thales, beberapa pesawat angkut sedang maupun berat, 6 UAV Heron, serta simulator Sukhoi. ${ }^{5}$

\section{Security}

Keamanan, seperti yang telah didefinisikan oleh Barry Buzan "Security, in any objective sense, measures the absence of threat to acquired values, in a subjective sense, the absence of fear that such values will be attacked"6 merupakan suatu landasan yang dapat dijadikan sebagai dasar pembentukan bagi penentuan arah kebijakan Pertahanan Indonesia.

Beberapa elemen yang terdapat pada Security ini yakni diantaranya

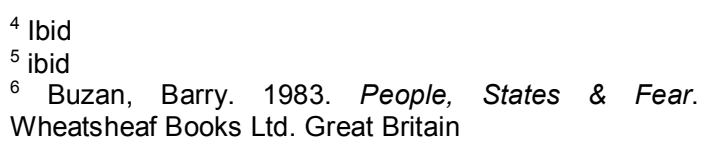
Wheatsheaf Books Ltd. Great Britain 
adalah actor, common issue yang dapat menjadi ancaman (threat), speech of act, serta public/audience. Kita dapat memposisikan Pemerintah Republik Indonesia sebagai pelaku (actor) yang mendefinisikan dan menentukan apa yang akan menjadi ancaman dan bagaimana tindakan speech of act-nya. Ancaman (threat) yang akan berpotensi masuk ke dalam wilayah Indonesia, misal pelanggaran batas wilayah perbatasan, terorisme, illegal fishing, illegal logging, drugs-trafficking, dan sebagainya.

Speech Act yang dapat dilakukan Pemerintah Republik Indonesia adalah bagaimana Pemerintah berusaha mempengaruhi publik untuk menjadikan satu hal sebagai ancaman keamanan yang sedang dihadapi. Untuk prosesnya, Dewan Keamanan Nasional yang telah merumuskan draft ancaman keamanan nasional dapat membawa hal tersebut ke Dewan sehingga nantinya akan disahkan sebagai ancaman keamanan nasional.

Selama ini, Pemerintah Indonesia belum menentukan dan mendefinisikan hal-hal yang berpotensi menjadi ancaman keamanan nasional secara jelas dan mendetil dalam kebijakan resminya. Dampaknya antara lain adalah Indonesia belum dapat mengukur kemampuan dan kekuatan keamanan nasionalnya sendiri karena tidak memiliki target yang dapat menjadi acuan atau tolok ukur sekaligus pembanding terhadap kekuatan keamanan nasionalnya.

Kita tidak dapat menafikkan bahwa sampai kementeriankementerian yang ada belum memiliki langkah-langkah strategis yang terkoordinasi untuk menangkal hal-hal yang dapat berpotensi menjadi ancaman keamanan nasional bagi Indonesia. Ini menjadi dampak lain dari belum ditentukan dan didefinisikannya ancaman keamanan nasional. Akibatnya adalah kinerja para stakeholders tidak dapat sejalan dan sudah pasti ancaman keamanan nasional akan sangat sulit untuk dapat diselesaikan secara kolektif dan berkesinambungan.

\section{Deterrence}

Scelling dalam karyanya The Strategy of Conflict mendefinisikan "detterence is concerned with influencing the choices another party will make, and doing it by influencing his expectations of how we will hehave. It involves confronting him with evidence for believing that our behavior will be determined by his behavior."

Persyaratan pertama yang harus dipenuhi sebuah negara agar efek deterrence atau daya gentar ini

\footnotetext{
${ }^{7}$ Schelling, Thomas C., 1960, The Strategy of Conflict, Cambridge, MA: Harvard University Press
} 
berfungsi, menurut Spiegel (2004), adalah Komitmen. Hal komitmen negara dibutuhkan dalam tahapan yang bersifat definitif dan spesifik. Tahap selanjutnya akan rapuh jika tahap pertama ini belum jelas atau masih bersifat ambigu.

Persyaratan kedua yakni Kapabilitas. Jika kita melihat lagi makna deterrence, yakni meyakinkan negara lain bahwa melakukan penyerangan adalah sebuah kesalahan karena negaranya memiliki kapabiltas untuk menyerang balik negara lawan, maka Pemerintah diwajibkan untuk melihat kapabiltas tiap matra, sumber daya, maupun elemen pertahanan yang dimilikinya.

Persyaratan terakhir yakni Kredibilitas. Suatu kredibilitas dibutuhkan negara dalam menyusun komitmen dan membangun kapabilitas agar meyakinkan negara lain tidak melakukan agresi kepada negara yang dalam posisi bertahan.

Melihat Kebijakan Amerika Serikat dibawah Presiden Trump khususnya terhadap kawasan Asia Tenggara, peningkatan ekonomi dan militer China, konstalasi sengketa di Laut China Selatan, serta arm race di semenanjung Korea setidaknya sudah dapat menjadi perhitungan bagi Pemerintah Indonesia untuk meningkatkan daya gentar bagi kapabilitas matra, sumber daya, maupun elemen domestik yang dimilikinya.

Peningkatan kapabilitas matra dan sumber daya dapat dilakukan melalui pembangunan industri pertahanan, dan urgensi dari pembangunan industri pertahanan inilah yang akan menghasilkan efek daya gentar Indonesia, serta multiple effect baik dalam bidang perekonomian maupun peningkatan teknologi domestik.

\section{Arm Candy}

Menurut MacMillan Dictionary, definisi arm candy adalah "an attractive person that you take to a social event because they are attractive rather than because they are intelligent or because you are having a romantic relationship with them."

Bila dianalogikan bahwa 'seseorang' tersebut adalah alutsista yang dipilih dan difungsikan oleh suatu negara hanya karena alutsista tersebut semata-mata hanya bersifat atraktif dan menarik perhatian, bukan karena fungsi dan kapabilitasnya yang sesuai dengan karakter negara ini.

Di satu sisi, perjalanan industri pertahanan domestik masih di tahap pembelajaran awal, dan di sisi lain, target pemenuhan alutsista sudah berlari mendahului kapabilitas industri pertahanan sehingga dua variabel MEF ini saling kejar mengejar. Hal ini 
menjadikan belum maksimalnya penyelarasan kapabilitas industri pertahanan, target pengguna, dan anggaran negara.

Permasalahan yang dihadapi industri pertahanan domestik diantaranya adalah, pertama, masih rendahnya alih maupun serapan teknologi pada industri pertahanan domestik, yang pada nantinya pula berbanding lurus dengan masih minimnya kualitas dan kuantitas produkproduk yang dihasilkan.

Tingginya cost pada sektor penanaman modal dalam divisi penelitian dan pengembangan industri pertahanan tersebut menjadikan para stakeholders tidak dapat bergerak banyak. Alhasil negara masih membutuhkan pembelian alutsista dari industri pertahanan mancanegara.

Adanya anggapan bahwa pangsa pasar industri pertahanan yang terbatas, menyebabkan para stakeholders masih mematok harga produknya yang cukup tinggi. Belum adanya kepastian pemesanan dan masih belum kuatnya alur hulu ke hilir, maupun sebaliknya, pun pada akhirnya tidak dapat memproduksi banyak varian dari produk-produk yang sudah umum dihasilkan.

Meskipun kemandirian industri pertahanan tidak dapat dihasilkan semudah membalikkan telapak tangan, setidaknya Pemerintah dapat melaksanakan tahap demi tahap menuju ke kemandirian tersebut, yang dimulai dari pembelajaran dalam pengoperasian alutsista tersebut, lalu perawatan dan peningkatan kandungan lokal.

Tahap selanjutnya adalah merekayasa dan merancang bangun dari produk-produk yang pernah ada, sehingga nanti akan menuju tahap kemandirian dengan kapabilitas mampu merancang dan membangun alutsista secara mandiri.

Pemerintah dalam hal ini tidak serta merta menjadi satu-satunya pihak yang paling bertanggung jawab dalam pembangunan industri pertahanan, akan tetapi masih ada pihak produsen yakni para industri pertahanan domestik dan pihak pengguna yakni Tentara Nasional Indonesia, Kepolisian Republik Indonesia, serta instansi lainnya. Ketiga pilar inilah yang wajib saling bersinergi dalam pembangunan industri pertahanan.

Pihak pengguna wajib menyusun taktik, strategi, maupun doktrin yang telah disesuaikan dengan anggaran negara. Sementara itu di pihak industri pertahanan masih harus memetakan potensi dan kemampuan masing-masing industrinya, serta menyelaraskan dengan kebutuhan dan anggaran pengguna. 
Bila dilihat dari masterplan pembangunan industri pertahanan, program-program di tahap pertama (2010-2014) yakni penetapan program, stabilisasi dan optimalisasi, persiapan regulasi, serta persiapan new future products. Program di tahap kedua (2015-2019) yakni mendukung MEF, peningkatan kemampuan kerjasama produksi, serta pembangunan new product.

Tahap ketiga (2020-2024) memiliki program yaitu mendukung postur ideal, pengembangan industri, serta peningkatan kerjasama internasional. Di tahap keempat (2025-2029), programnya adalah kemandirian industri pertahanan, kemampuan berkolaborasi secara internasional, serta pengembangan yang berkelanjutan.

Ada beberapa langkah yang wajib dilakukan oleh Indonesia dibawah kepemimpinan Presiden Joko Widodo ini yakni Pertama, mensinergikan tiga pilar industri pertahanan, yakni pilar Produsen, pilar Pengguna, serta pilar Pemerintah sendiri agar dapat saling bersinergi dan tidak saling mendahului pilar lainnya.

Kedua, tetap mendukung proses profesionalisme TNI, dengan beberapa cara yakni meningkatkan kesejahteraan prajurit dan meningkatkan pos khusus dari APBN, minimal tetap mempertahankan kenaikan 1,5\%.
Adanya jaminan peningkatan kesejahteraan TNI dan keluarganya juga merupakan pembangunan sumber daya manusia pada level individu kombatan. Pemerintah wajib mengalokasikan dana segar untuk memakmurkan prajurit agar kapabilitas dan kualitas mereka juga seiring bertambah. Dengan demikian, tidak ada alasan strategi pertahanan nasional lemah karena minimnya kesejahteraan para prajurit beserta keluarganya, serta menjadikan mereka untuk selalu meningkatkan profesionalisme di tubuh TNI.

Ketiga, merevisi grand design MEF, dan membangun industri pertahanan Indonesia secara profesional dan dapat menghasilkan multiple effect, yakni economic effect dan technology effect.

Terakhir, menempatkan kebijakan pertahanan sebagai bagian dari sistem keamanan nasional yang dikelola oleh Dewan Keamanan Nasional. Sesuai dengan yang telah disinggung diatas yaitu Pemerintah Republik Indonesia untuk dapat mendefinisikan hal apa yang dapat berpotensi besar menjadi ancaman keamanan nasional bagi Negara Republik Indonesia sehingga nantinya dapat menjadi deterrence terhadap hal-hal yang berpotensi menjadi ancaman negara Indonesia. 


\section{Penutup}

Semakin besar suatu negara, akan semakin besar dan berlipat pula jumlah ancamannya. Jika negara tersebut belum bisa menentukan siapa, dalam bentuk apa, dan dari mana ancaman itu berasal, maka negara tersebut tidak akan pernah mencapai kondisi keamanannya yang ideal. Untuk mencapai keamanan yang ideal, maka negara tersebut wajib memperkuat dirinya sendiri.

Industri strategis pertahanan Indonesia akan tumbuh kuat jika didukung penuh oleh Pemerintah Republik Indonesia melalui kebijakan pertahanannya. Kebijakan pertahanan Indonesia semestinya meliputi dukungan penuh dana, teknologi, dan teknis dari Pemerintah Indonesia untuk industri strategis pertahanan domestik sehingga pihak industri dapat memenuhi standar kekuatan minimal TNI di masa mendatang.

\section{Daftar Pustaka}

Budiardjo, Prof. Miriam, 1999, DasarDasar IImu Politik, 20 ${ }^{\text {th }}$ Ed., Jakarta; PT. Gramedia Pustaka Utama

Buzan, Barry, 1983, People, States \& Fear. Wheatsheaf Books Ltd. Great Britain
Buzan, Barry, Wæver, Ole, de Wilde, Jaap, 1998, Security: A New Framework for Analysis. London

Suryohadiprojo, Sayidiman, Pengantar IImu Perang, Jakarta, Pustaka Intermasa, 2008

Peraturan Presiden Republik Indonesia nomor 41 tahun 2010 tentang Kebijakan Umum Pertahanan Negara

Hingga Tahun Ini, Alutsista TNI Baru 50 Persen MEF pada website Jurnal Maritim:

http://jurnalmaritim.com/2014/1/91

4/hingga-tahun-ini-alutsista-tnibaru-50-persen-mef, diakses pada 29 Maret 2017

MEF: Modernisasi Militer Indonesia pada website http://analisismiliter.com/artikel/par t/20/MEF_Modernisasi_Militer_Ind onesia, diakses pada 29 Maret 2017

Schelling, Thomas C., 1960, The Strategy of Conflict, Cambridge, MA: Harvard University Press

The Indonesian Forum Seri 27 "Satu Tahun UU Industri Pertahanan, Meneropong Kekuatan Alutsista Indonesia" pada website The Indonesian Institute: http://theindonesianinstitute.com/th e-indonesian-forum-seri-27-satutahun-uu-industri-pertahananmeneropong-kekuatan-alutsista- 
indonesia/, diakses pada 29 Maret 2017

The Jakarta Post. 2014. Indonesia's Arm Candy: Quantity vs Capability Dilemma. $13 \quad$ Maret. http://www.thejakartapost.com/ne ws/2014/03/13/indonesia-s-armcandy-quantity-vs-capabilitydilemma.html diakses pada 20 April 2017 